\title{
Effect of Material Composition on Cohesion Characteristics of Styrene-Butadiene-Styrene-Modified Asphalt Using Surface Free Energy
}

\author{
Xing-jun Zhang, ${ }^{1,2}$ Hui-xia Feng, ${ }^{1}$ Xiao-min Li, ${ }^{3}$ Xiao-yu Ren, ${ }^{2,3}$ Zhen-feng Lv, ${ }^{4}$ and Bo Li \\ ${ }^{1}$ School of Petrochemical Engineering, Lanzhou University of Technology, Lanzhou 730050, China \\ ${ }^{2}$ Gansu Province Highway Maintenance Engineering Research Center, Lanzhou 730070, China \\ ${ }^{3}$ Key Laboratory of Road \& Bridge and Underground Engineering of Gansu Province, Lanzhou Jiaotong University, \\ Lanzhou 730070, China \\ ${ }^{4}$ School of Highway, Chang'an University, Xian 710064, China
}

Correspondence should be addressed to Bo Li; libolzjtu@hotmail.com

Received 14 April 2017; Revised 22 June 2017; Accepted 13 August 2017; Published 26 September 2017

Academic Editor: Meor Othman Hamzah

Copyright (C) 2017 Xing-jun Zhang et al. This is an open access article distributed under the Creative Commons Attribution License, which permits unrestricted use, distribution, and reproduction in any medium, provided the original work is properly cited.

Styrene-butadiene-styrene- (SBS-) modified asphalts were prepared by mixing different base asphalts, SBS modifier, extracting oil, and stabilizing agents. The contact angles between SBS-modified asphalt and distilled water, glycerol, and formamide were detected by the sessile drop method. Based on the surface energy theory, the surface free energy and cohesive power of SBS-modified asphalt were calculated. The influence of the raw materials composition, such as the virgin asphalt and SBS modifier types as well as the extracting oil and stabilizing agent contents, on the cohesive characteristics of SBS-modified asphalt was discussed. The results showed that virgin asphalt was compatible with SBS modifiers to improve cohesiveness. The cohesive power of branched SBSmodified asphalt was larger than that of linear SBS-modified asphalt. The cohesion of SBS-modified asphalt was improved as the SBS modifier and stabilizer contents increased but was reduced for excessive extraction oil contents. The cohesive characteristics of the SBS-modified asphalt were improved by the formation of stable three-dimensional network structures by cross-linking, winding, and grafting among different raw materials.

\section{Introduction}

Asphalt is a mixture of crude oil refining residue and various chemical components, widely used in the road pavement industry as an aggregate binder, because it offers good adhesion, viscoelasticity, and strength [1]. However, further applications are restricted by disadvantages including high-temperature rutting and low-temperature cracking [2]. Heavier vehicle loads, increased traffic volumes, and extreme weather conditions can cause pavement damage such as permanent deformation [3, 4]. In order to improve the quality of asphalt, various polymers can be incorporated by mechanical mixing or chemical reaction, thereby improving the mechanical properties, heat sensitivity, and aging resistance of the asphalt
$[5,6]$. The most commonly used polymers are styrenebutadiene-styrene (SBS) block copolymers. SBS block copolymers are known to improve the low- and high-temperature performance of bitumen [7].

SBS-modified asphalt is a composite prepared by mixing neat asphalt, SBS modifier, extracting oil, and stabilizing agents [8]. For SBS block copolymers mixed with neat asphalt, the system gradually becomes a two-phase structure in which polymer phases formed by maltenes-swelling polymers are dispersed in the asphalt-rich phase [9]. Therefore, the compatibility between asphalt and SBS is considered critical, with a profound impact on the thermal mechanical properties, rheological properties, and morphology [10, 11]. Generally, asphalt comprises saturated hydrocarbons, aromatics, resins, 
TABLE 1: Properties of neat asphalts.

\begin{tabular}{lcccc}
\hline Performance & Unit & Binder A & Binder B & Binder C \\
\hline Penetration $\left(25^{\circ} \mathrm{C}, 100 \mathrm{~g}, 5 \mathrm{~s}\right)$ & $0.1 \mathrm{~mm}$ & 85.5 & 84.3 & 87.6 \\
Softening point $($ ring ball method) & ${ }^{\circ} \mathrm{C}$ & 45.6 & 48.7 & $>100$ \\
Ductility $\left(5 \mathrm{~cm} / \mathrm{min}, 15^{\circ} \mathrm{C}\right)$ & $\mathrm{cm}$ & $>100$ & & \\
\hline & Residue after aging under rotary film oven $\left(163^{\circ} \mathrm{C}, 85 \mathrm{~min}\right)$ & & \\
Loss of quality & $\%$ & 0.07 & 0.18 & 0.12 \\
Penetration ratio & $\%$ & 70 & 64 & 61 \\
Ductility $\left(5 \mathrm{~cm} / \mathrm{min}, 10^{\circ} \mathrm{C}\right)$ & $\mathrm{cm}$ & 9.0 & 6.5 & 8.0 \\
\hline
\end{tabular}

and asphaltenes in solvents, the ratio of which is commonly referred to as the SARA fraction [1]. However, each component has a different solubility parameter and thus a different level of compatibility with the polystyrene (PS) and polybutadiene (PB) blocks in the SBS. Some efforts $[12,13]$ have investigated the compatibility between asphaltic components and SBS copolymers. As a rule of thumb, asphalt with higharomatic contents or linear SBS can form compatible and stable SBS-modified asphalt $[14,15]$. Moreover, incompatibility between asphalt and polymer can be avoided by adding aromatic oils or stabilizing agents to the mixture $[12,16]$. While some authors have studied the effects of the raw materials on the performance of SBS-modified asphalt roads to guide the production and application of SBS-modified asphalts, the cohesion characteristics of SBS-modified asphalt are still unclear.

Moisture damage of asphalt pavement, related to the breakdown of the asphalt composite, can be caused by losses in asphalt-asphalt cohesion and/or aggregate-binder adhesion $[17,18]$. Cohesion is the molecular attraction existing between two similar objects in close contact, such as the internal binding interactions in asphalt $[19,20]$. The work of cohesion of the asphalt binder is strongly related to the fatigue cracking characteristics of asphalt mastics and mixtures [21]. The cohesive properties of the binder and mastic determine the fracture resistance of asphalt concrete [22]. The surface free energy of the asphalt binder can be used to characterize the work of cohesion [23, 24]. Cheng et al. found that aging processes can decrease the cohesion of asphalt via an investigation of the cohesion characteristics of asphalt binders based on surface free energy [25]. Tan and Guo tested the cohesion and adhesion of asphalt mastic using the surface free energy method, reporting that the work of cohesion of neat asphalt is greater than that of modified asphalt [26]. Most previous studies have focused on the surface free energy of neat and modified asphalt binders [27-29]. However, few have considered the influence of raw materials composition on the cohesion characteristics of SBS-modified asphalt.

The objective of this study was to investigate the influence of the raw materials composition on the cohesion characteristics of SBS-modified asphalt using the surface free energy. SBS-modified asphalts were prepared by mixing different base asphalts, SBS modifier, extracting oil, and stabilizing agent. The contact angles between SBS-modified asphalt and distilled water, glycerol, and formamide were detected by the sessile drop method. Based on surface energy theory, the surface free energy and cohesive power of the SBS-modified asphalts were calculated. The influence of the raw materials composition, such as virgin asphalt, SBS modifier types, and contents of extracting oil and stabilizing agent on the cohesive characteristics were discussed for SBS-modified asphalt.

\section{Raw Materials and Preparation Method of SBS-Modified Asphalt}

\subsection{Raw Materials}

2.1.1. Neat Asphalt. Three kinds of asphalt used in the Gansu area, such as binder A, binder B, and binder $\mathrm{C}$, were selected as virgin asphalts. They were provided by Gansu Luqiao Construction Group Maintenance Technology Co., Ltd. The main technical properties were tested according to Standard Test Methods of Bitumen and Bituminous Mixtures for Highway Engineering (JTG E20-2011) and results were shown in Table 1.

2.1.2. Modifier. SBS modifiers can be divided into linear and branched types according to their molecular structures. In this study, linear and branched SBS modifiers were used to prepare SBS-modified asphalt. The main technical indicators were tested according to thermoplastic elastomers styrenebutadiene block copolymer (SH/T 1610-2011) and results are shown in Table 2.

2.1.3. Furfural Extraction Oil. Furfural extraction oil was selected as a compatibility agent for preparing SBS-modified asphalt because it contains a high-aromatic fraction that can improve the proportion of matrix asphalt, promote compatibility between modifier and asphalt, and improve the compatibility of the SBS-modified asphalt. Furfural extraction oil can also improve the low-temperature plasticity and ductility of SBS-modified asphalt. In this study, the furfural extraction oil was provided by PetroChina's Lanzhou Refining Company. The main technical indicators of furfural extraction oil were tested according to ASTM D2007-91 MOD and results are shown in Table 3.

2.1.4. Stabilizer. Some stabilizer was added during the preparation of the SBS-modified asphalts in order to prevent internal phase separation and improve storage stability. In this study, a high-efficiency stabilizer developed by the Gansu 
TABLE 2: Properties of SBS modifiers.

\begin{tabular}{lcc}
\hline Index & Liner & Branched \\
\hline Block ratio (S/B) & $30 / 70$ & $40 / 60$ \\
Volatile content \% & 0.50 & 0.50 \\
$300 \%$ Tensile stress, MPa & 1.7 & 1.7 \\
Tensile strength, MPa & 12.0 & 12.0 \\
Elongation at break \% & 700 & 600 \\
Shore hardness, A & $75 \pm 7$ & $82 \pm 7$ \\
Melt flow rate (g/10 min) & $0.50 \sim 5.00$ & $0.00 \sim 1.00$ \\
\hline
\end{tabular}

TABLE 3: Properties of furfural extraction oil.

\begin{tabular}{lccc}
\hline Appearance & Viscosity $\left(40^{\circ} \mathrm{C}\right)(\mathrm{Pa} \cdot \mathrm{s})$ & Flash point, ${ }^{\circ} \mathrm{C}$ & Aromatic content, $\%$ \\
\hline Brown-black & 2500 & 200 & 55.0 \\
\hline
\end{tabular}

TABle 4: Properties of stabilizer.

\begin{tabular}{lcccc}
\hline Appearance & Apparent density $\left(\mathrm{g} / \mathrm{cm}^{3}\right)$ & Melting point, ${ }^{\circ} \mathrm{C}$ & Residue at 80 -mesh sieve, $\%$ & Water content, $\%$ \\
\hline Gray-black & $0.5 \sim 0.7$ & 120 & 0.1 & 0.2
\end{tabular}

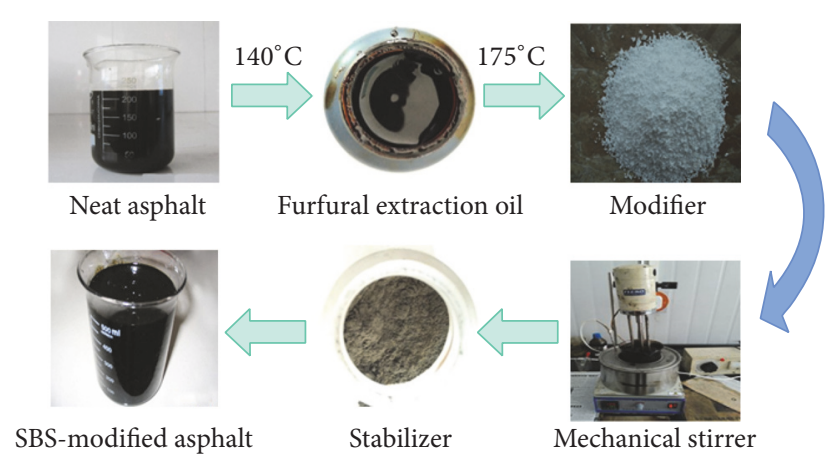

FIGURE 1: Preparation process of SBS-modified asphalts.

Provincial Engineering Research Center for Pavement Engineering is used. The main technical properties of the highefficiency stabilizer were tested according to Synthetic Hydrotalcite Thermal Stabilizer (HG/T 4495-2013) and results are shown in Table 4.

2.2. Preparation of SBS-Modified Asphalts. In order to compare the influence of different raw materials and their contents on the adhesion properties of the SBS-modified asphalts, each SBS-modified asphalt sample was prepared using the same process. Figure 1 shows the preparation process of SBS-modified asphalts. First, furfural extraction oil was added to the flowing virgin asphalt and quickly heated to $175^{\circ} \mathrm{C}-180^{\circ} \mathrm{C}$. Then, SBS modifier was added and the mixture was stirred for $5 \mathrm{~min}$ using a mechanical stirrer. The mixed asphalts were continuously sheared for $35 \mathrm{~min}$ at a speed of $5500 \mathrm{rpm}$ using a shearing and dispersing emulsifier. The high-efficiency stabilizer was added in the last $10 \mathrm{~min}$ of the shearing process. The mixed asphalts were placed in an oven for $2 \mathrm{~h}$ at $170^{\circ} \mathrm{C}$ for growth.

\section{Surface Free Energy Theory and Experiment}

3.1. Surface Free Energy Theory. Surface free energy is defined as the work by a material in a vacuum necessary to produce a new interface per unit area. According to analyses by Fowkes and Good, the surface energy of a material mainly comprises a polar component and nonpolar dispersive component $[30,31]$. Generally, the polar component of the surface free energy is the acid force and alkali force, while the dispersive component is composed of the Keesom orientation force, Debye induction force, and London dispersion force [32]. The surface free energies of liquid and solid materials can be expressed as follows [32]:

$$
\begin{aligned}
& \gamma_{l}=\gamma_{l}^{d}+\gamma_{l}^{p}, \\
& \gamma_{s}=\gamma_{s}^{d}+\gamma_{s}^{p},
\end{aligned}
$$

where $\gamma_{l}$ is the surface free energy of a liquid material; $\gamma_{s}$ is the surface free energy of a solid material; $\gamma_{l}^{d}$ is the dispersive component of surface free energy for liquid materials; $\gamma_{l}^{p}$ is the polar component of surface free energy for liquid materials; $\gamma_{s}^{d}$ is the dispersive component of surface free energy for solid materials; and $\gamma_{s}^{p}$ is the polar component of surface free energy for solid materials.

Fowkes indicated that the dispersive force between liquid and solid could be expressed as the geometric mean of the dispersive components of the liquid and solid surface free energies. Simultaneously, Owens and Wendt developed a similar method for the polar component [33]. Therefore, the surface free energy of the liquid-solid interface can be expressed as follows:

$$
\gamma_{s l}=\gamma_{s}+\gamma_{l}-2 \sqrt{\gamma_{s}^{d} \gamma_{l}^{d}}-2 \sqrt{\gamma_{s}^{p} \gamma_{l}^{p}}
$$


TABLE 5: Surface free energy of three probe liquids at $25^{\circ} \mathrm{C}$.

\begin{tabular}{lcccrr}
\hline Test the liquid & $\gamma_{L}$ & $\gamma_{L}^{d}$ & $\gamma_{L}^{p}$ & $\gamma_{L}^{+}$ & 25.50 \\
\hline Distilled water & 72.8 & 21.8 & 51.0 & 3.92 & 25.5 \\
Glycerin & 64.0 & 34.0 & 38.0 & 19.0 & 2.0 \\
Formamide & 58.0 & & 37.4 \\
\hline
\end{tabular}

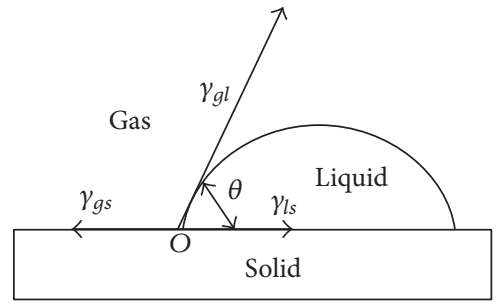

FIGURE 2: Young contact angle diagram.

Figure 2 shows the Young contact angle diagram between solid and liquid. The polar and dispersive components of the surface free energy can be calculated using the Young equation, which relates the surface free energy and liquidsolid contact angle and is expressed as follows [33]:

$$
\gamma_{l} \cos \theta=\gamma_{s}-\gamma_{s l}
$$

Fowkes proposed an equation to calculate the surface free energy though the dispersive component and contact angle. Oss calculated the surface free energy using the dispersion and polar components by developing (3) and (4) into (5) [33]:

$$
1+\cos \theta=2 \sqrt{\gamma_{s}^{d}}\left(\frac{\sqrt{\gamma_{l}^{d}}}{\gamma_{l}}\right)+2 \sqrt{\gamma_{s}^{p}}\left(\frac{\sqrt{\gamma_{l}^{p}}}{\gamma_{l}}\right)
$$

The surface free energy of a solid can be calculated using (5), generally expressed as follows:

$$
\frac{1+\cos \theta}{2} \frac{\gamma_{l}}{\sqrt{\gamma_{l}^{d}}}=\sqrt{\gamma_{s}^{d}}+\sqrt{\gamma_{s}^{p}}\left(\frac{\sqrt{\gamma_{l}^{p}}}{\gamma_{l}^{d}}\right) .
$$

The dispersive component $\sqrt{\gamma_{s}^{d}}$ and polar component $\sqrt{\gamma_{s}^{p}}$ can be obtained through linear analysis by (6).

3.2. Cohesive Power of Asphalt. The work of cohesion is defined as the energy necessary to produce two new surfaces in a homogeneous material and is equal to twice the surface free energy. The equation for the work of cohesion is as follows [26]:

$$
W_{\text {cohesion }}=2 \gamma_{a}
$$

where $\gamma_{a}$ is the surface free energy of asphalt.

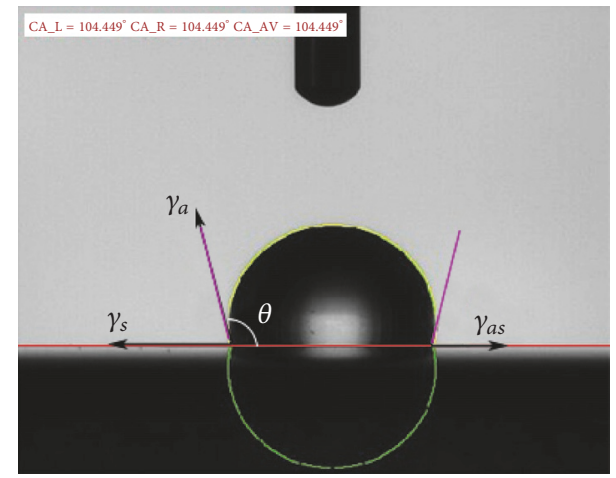

FIGURE 3: Schematic of the contact angle formed between a probe liquid and asphalt surface.

3.3. Contact Angle Measurement. In order to calculate the cohesion index of the asphalt, the surface free energy and its components must be obtained. According to the analysis of (5), the surface free energy and its components can be calculated using the contact angle between the solid asphalt and three liquids with known surface energy parameters $[24,31,34]$. In this study, the three liquids of distilled water, glycerin, and formamide were used as probe liquids in contact angle measurements. The surface free energy parameters of the three probe liquids are shown in Table 5.

The sessile drop method was used to conduct the surface free energy measurements in this study. This is an optical contact angle technique used to measure the contact angles between asphalt and the probe liquids [24, 34]. A schematic of the contact angle formed between the probe liquid and asphalt surface can be seen in Figure 2. The asphalt binder samples were prepared by heating at $163^{\circ} \mathrm{C}$ and then pouring into small plates, which had been previously placed on a heater to attain the constant temperature of $60^{\circ} \mathrm{C}$. The plates with asphalt binder were heated by another heater to $163^{\circ} \mathrm{C}$ for approximately $5 \mathrm{~min}$ to create an even, thin film coating on the surface of the plate. Afterward, the samples were cooled to room temperature and kept in desiccators for $12 \mathrm{~h}$ at room temperature before testing. As shown in Figure 3, the instrument used to measure the contact angle is a drop shape analyzer (Binder A200KB) made in USA which is composed of an illumination device, a charge-coupled device (CCD) camera, three microsyringes with needles built into the machine, and image analysis software (Figure 4). The measurement was performed at room temperature. Each liquid drop was individually dropped at five different locations of the asphalt film and the contact angle was measured. The average contact angle from the five measurements per film was recorded. 
TABLE 6: Contact angle and its variation coefficient for the SBS-modified asphalts.

\begin{tabular}{|c|c|c|c|c|c|c|}
\hline & \multicolumn{2}{|c|}{ Distilled water } & \multicolumn{2}{|c|}{ Glycerol } & \multicolumn{2}{|c|}{ Formamide } \\
\hline & Average value $\left(^{\circ}\right)$ & $\begin{array}{l}\text { Coefficient of } \\
\text { variation (\%) }\end{array}$ & Average value $\left({ }^{\circ}\right)$ & $\begin{array}{l}\text { Coefficient of } \\
\text { variation (\%) }\end{array}$ & Average value $\left({ }^{\circ}\right)$ & $\begin{array}{l}\text { Coefficient of } \\
\text { variation (\%) }\end{array}$ \\
\hline Binder A & 102.6 & 0.43 & 92.6 & 0.36 & 86.1 & 0.32 \\
\hline Binder B & 100.6 & 0.48 & 93.8 & 0.28 & 86.9 & 0.63 \\
\hline Binder C & 103.8 & 0.25 & 97.8 & 0.48 & 92.0 & 0.47 \\
\hline $\begin{array}{l}\text { Binder A + linear } \\
\text { SBS }\end{array}$ & 94.0 & 0.29 & 89.6 & 0.39 & 82.0 & 0.18 \\
\hline $\begin{array}{l}\text { Binder B + linear } \\
\text { SBS }\end{array}$ & 96.6 & 0.44 & 89.2 & 0.35 & 83.0 & 0.39 \\
\hline $\begin{array}{l}\text { Binder } \mathrm{C}+\text { linear } \\
\text { SBS }\end{array}$ & 95.4 & 0.50 & 90.6 & 0.50 & 84.1 & 0.29 \\
\hline $\begin{array}{l}\text { Binder A + } \\
\text { branched SBS }\end{array}$ & 92.4 & 0.53 & 87.2 & 0.17 & 79.6 & 0.47 \\
\hline $\begin{array}{l}\text { Binder B }+ \\
\text { branched SBS }\end{array}$ & 95.6 & 0.35 & 88.0 & 0.57 & 80.9 & 0.48 \\
\hline $\begin{array}{l}\text { Binder C }+ \\
\text { branched SBS }\end{array}$ & 94.7 & 0.44 & 89.6 & 0.50 & 82.5 & 0.57 \\
\hline $\begin{array}{l}\text { Binder A }+3.5 \% \\
\text { SBS }\end{array}$ & 96.2 & 0.31 & 89.8 & 0.38 & 83.8 & 0.46 \\
\hline $\begin{array}{l}\text { Binder A + 4.0\% } \\
\text { SBS }\end{array}$ & 94.9 & 0.35 & 89.4 & 0.64 & 82.9 & 0.52 \\
\hline $\begin{array}{l}\text { Binder A + 4.5\% } \\
\text { SBS }\end{array}$ & 94.0 & 0.29 & 89.6 & 0.39 & 82.0 & 0.18 \\
\hline $\begin{array}{l}\text { Binder A }+5.0 \% \\
\text { SBS }\end{array}$ & 93.6 & 0.31 & 86.8 & 0.39 & 78.9 & 0.38 \\
\hline $\begin{array}{l}\text { Binder A + 0\% } \\
\text { extraction oil }\end{array}$ & 96.8 & 0.25 & 90.4 & 0.40 & 84.3 & 0.31 \\
\hline $\begin{array}{l}\text { Binder A + } 2.5 \% \\
\text { extraction oil }\end{array}$ & 93.3 & 0.37 & 88.0 & 0.52 & 81.5 & 0.43 \\
\hline $\begin{array}{l}\text { Binder A + 3.5\% } \\
\text { extraction oil }\end{array}$ & 94.0 & 0.29 & 89.6 & 0.39 & 82.0 & 0.18 \\
\hline $\begin{array}{l}\text { Binder } A+4.5 \% \\
\text { extraction oil }\end{array}$ & 93.4 & 0.33 & 87.4 & 0.32 & 81.0 & 0.39 \\
\hline $\begin{array}{l}\text { Binder A + 0\% } \\
\text { stabilizer }\end{array}$ & 97.2 & 0.35 & 91.0 & 0.28 & 85.2 & 0.17 \\
\hline $\begin{array}{l}\text { Binder A + 0.1\% } \\
\text { stabilizer }\end{array}$ & 95.3 & 0.45 & 88.6 & 0.52 & 82.5 & 0.30 \\
\hline $\begin{array}{l}\text { Binder A + } 0.2 \% \\
\text { stabilizer }\end{array}$ & 94.0 & 0.29 & 89.6 & 0.39 & 82.0 & 0.18 \\
\hline $\begin{array}{l}\text { Binder A + 0.3\% } \\
\text { stabilizer }\end{array}$ & 92.8 & 0.40 & 86.1 & 0.25 & 78.5 & 0.52 \\
\hline
\end{tabular}

\section{Results and Discussion}

4.1. Contact Angle and Its Variation Coefficient. The contact angles and variation coefficients for the SBS-modified asphalts prepared with different raw materials and the three probe liquids were measured by the sessile drop method. The variation coefficient is the ratio of the standard deviation to the average value of the contact angle between the SBSmodified asphalts and each of the three probe liquids, used to investigate whether the contact angle test has good repeatability. The results are shown in Table 6. From statistical analysis, it is found that the coefficient of variation of the contact angle test results is in the range of $0.18 \%-0.64 \%$. These results indicate that the contact angle test results of the SBSmodified asphalts prepared with different raw materials and three probe liquids have good reproducibility.

4.2. Surface Energy of Modified Asphalt. The surface free energy parameters of the three test liquids and the contact angles between them and each of the SBS-modified asphalts were substituted into (5). The component values of the surface free energy of each SBS-modified asphalt were calculated by solving (6). According to (2), the surface free energies of the individual SBS-modified asphalts were obtained. The 
TABLE 7: Surface free energy of SBS-modified asphalts.

\begin{tabular}{|c|c|c|c|}
\hline \multirow{2}{*}{ Asphalt type } & \multicolumn{3}{|c|}{ Surface energy and its components } \\
\hline & Surface free energy & Dispersion component & Polar component \\
\hline Binder A & 18.47 & 17.17 & 1.30 \\
\hline Binder B & 18.84 & 18.06 & 0.77 \\
\hline Binder C & 15.10 & 14.00 & 1.10 \\
\hline Binder A + linear SBS & 22.14 & 21.96 & 0.18 \\
\hline Binder B + linear SBS & 19.60 & 17.40 & 2.20 \\
\hline Binder $\mathrm{C}+$ linear SBS & 19.68 & 18.39 & 1.29 \\
\hline Binder A + branched SBS & 23.38 & 22.63 & 0.74 \\
\hline Binder B + branched SBS & 22.12 & 20.74 & 1.38 \\
\hline Binder C + branched SBS & 21.10 & 20.14 & 0.96 \\
\hline Binder A + 3.5\% SBS & 18.93 & 16.58 & 2.35 \\
\hline Binder $\mathrm{A}+4.0 \% \mathrm{SBS}$ & 20.15 & 18.49 & 1.66 \\
\hline Binder $\mathrm{A}+4.5 \% \mathrm{SBS}$ & 22.14 & 21.96 & 0.18 \\
\hline Binder $\mathrm{A}+5.0 \%$ SBS & 24.12 & 23.27 & 0.85 \\
\hline Binder A + 0\% extraction oil & 18.84 & 16.75 & 2.09 \\
\hline Binder $A+2.5 \%$ extraction oil & 20.89 & 19.02 & 1.88 \\
\hline Binder $\mathrm{A}+3.5 \%$ extraction oil & 22.14 & 21.96 & 0.18 \\
\hline Binder $\mathrm{A}+4.5 \%$ extraction oil & 20.91 & 18.66 & 2.25 \\
\hline Binder A + $0 \%$ stabilizer & 18.12 & 15.87 & 2.25 \\
\hline Binder A + 0.1\% stabilizer & 19.72 & 17.30 & 2.42 \\
\hline Binder $\mathrm{A}+0.2 \%$ stabilizer & 22.14 & 21.96 & 0.18 \\
\hline Binder $\mathrm{A}+0.3 \%$ stabilizer & 23.89 & 22.68 & 1.21 \\
\hline
\end{tabular}

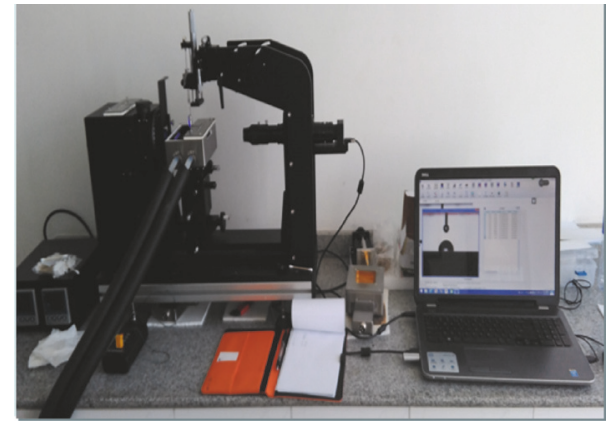

FIgURE 4: Drop shape analyzer.

surface free energies of the different SBS-modified asphalts range from $15.10 \mathrm{~mJ} / \mathrm{m}^{2}$ to $23.38 \mathrm{~mJ} / \mathrm{m}^{2}$, which is close to the range of surface free energy reported in the literature [35]. As shown in Table 7, the dispersion component is the major part of the surface free energy of the asphalt, compared to the polar component. Wei et al. also reported a similar conclusion and attributed it to the main component of the asphalt being nonpolar hydrocarbons [28]. In addition, with the increase of the content of SBS modifier, the total surface energy and dispersion component of the SBS-modified asphalt are gradually increased, while the polarity components of the SBSmodified asphalts generally decline at the different degrees. The surface free energy of the SBS-modified asphalt first increases and then decreases with increasing extraction oil content. For the extraction oil content of $3.5 \%$, the surface free energy of SBS-modified asphalt is maximized. The surface free energy of SBS-modified asphalt increases as the amount of stabilization agent increases.

The reliability and effectiveness of the surface free energy results were evaluated using a method developed by Kwok and Neumann [34]. They conclude that the values of $\gamma_{l} \cos \theta$ and $\gamma_{l}$ should show a linear relationship for a given solid with a variety of liquids. If the resulting curve is nonlinear, the results must be remeasured. Using the surface free energy result of asphalts with different SBS modifier contents as an example, the illustration of $\gamma_{l} \cos \theta$ and $\gamma_{l}$ for asphalt is given in Figure 5. It is observed that each asphalt sample shows a good linear fit between $\gamma_{l} \cos \theta$ and $\gamma_{1}$, with the coefficient of determination $\left(R^{2}\right)$ values varying from 0.9612 to 0.9995 . According to this method, $\gamma_{l} \cos \theta$ and $\gamma_{l}$ of other groups of SBS-modified asphalts and test liquids are regressed; all show linear correlation coefficients $>0.95$. This indicates that the contact angles between the SBS-modified asphalts prepared with different raw materials and the three probe liquids by the sessile drop method are accurate and that the surface free energy results of the SBS-modified asphalts can be used.

4.3. The Influence of Neat Asphalt Type on Cohesive Work of SBS-Modified Asphalt. Figure 6 presents the results of the cohesive work of different neat asphalts and SBS-modified asphalts. In general, the cohesive work of binder B asphalt is the highest among the three neat asphalts, while the cohesive work of binder $\mathrm{C}$ asphalt is the lowest. For asphalts with linear modifiers, the cohesive work of the binder A + SBS-modified 


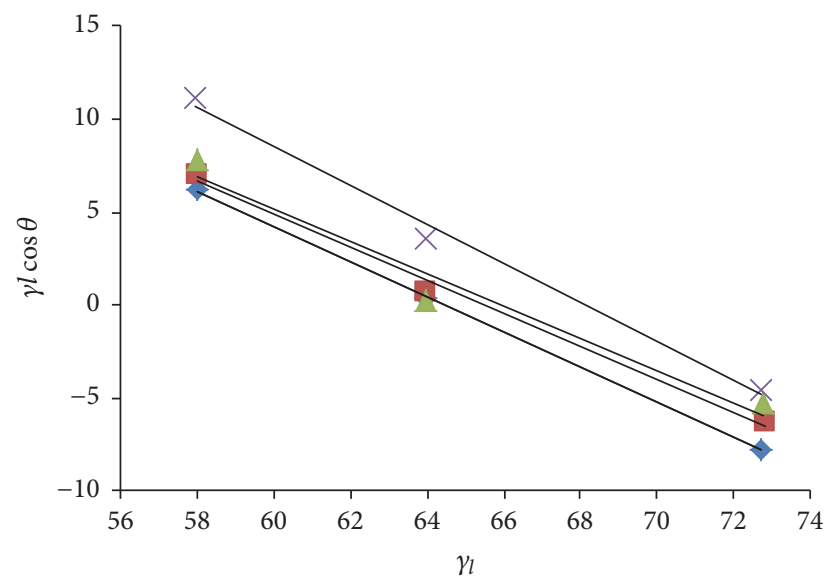

$3.5 \%$ SBS $R^{2}=0.9996 \triangle 4.5 \%$ SBS $R^{2}=0.9606$

$4.0 \%$ SBS $R^{2}=0.993 \times 5.0 \%$ SBS $R^{2}=0.9931$

FIgURE 5: Plot of $\gamma_{l}$ versus $\gamma_{l} \cos \theta$.

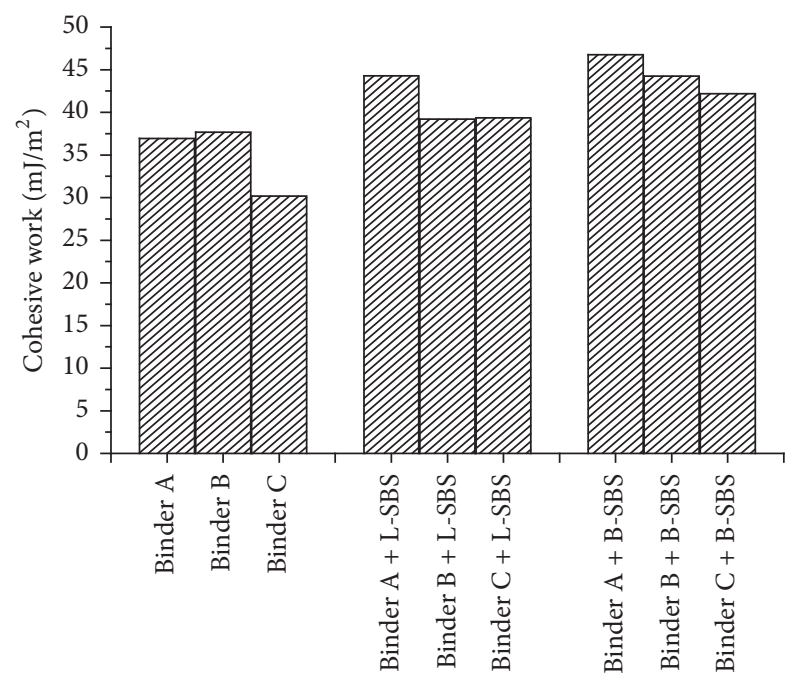

FIGURE 6: The cohesive work of SBS-modified asphalt prepared from different neat asphalts.

asphalt is the highest, while that of binder B + SBS-modified asphalt is equal to that of binder $\mathrm{C}+$ SBS-modified asphalt. The cohesion of binder $\mathrm{A}$, binder $\mathrm{B}$, and binder $\mathrm{C}$ asphalts is increased by $19.86 \%, 4.04 \%$, and $30.34 \%$, respectively, when the same amounts of linear SBS modifiers are added. For the three types of branched SBS-modified asphalt, the cohesive power ranks in the order of binder A + branched SBSmodified asphalt, binder B + branched SBS-modified asphalt, and binder $\mathrm{C}+$ SBS-modified asphalt. From the above results, it can be seen that the same SBS modifier has different modification effects on different neat asphalts, demonstrating the compatibility problems between SBS modifiers and neat asphalts from the perspective of cohesive properties.

4.4. Effect of SBS Type on Cohesive Work of SBS-Modified Asphalts. In order to compare and analyze the influence of SBS type on the surface energy of SBS-modified asphalt, the

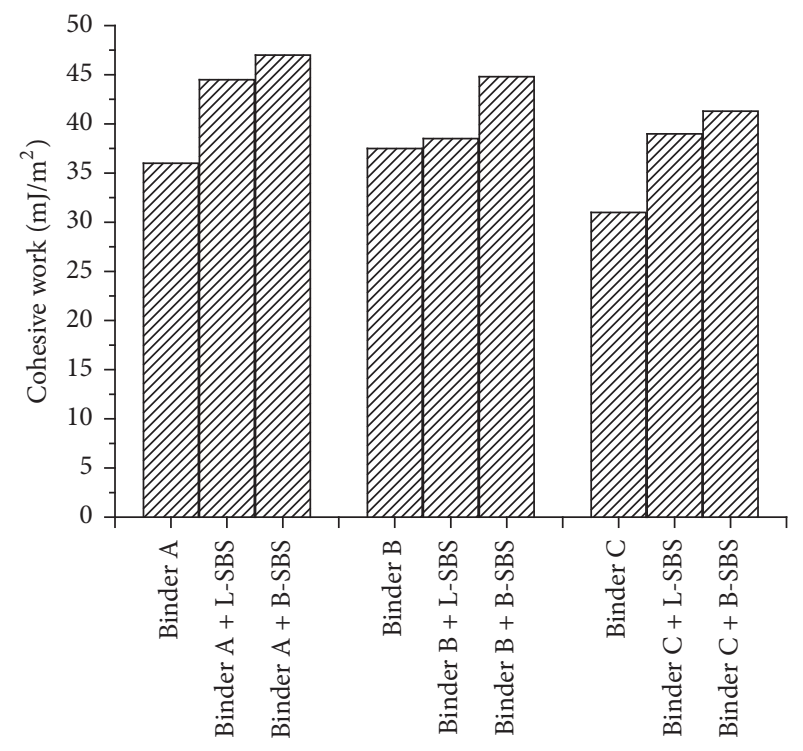

FIGURE 7: The cohesive work of SBS-modified asphalts prepared by different SBS types.

cohesive work values of the nine asphalt samples obtained in the previous section are arranged according to different SBS modifiers with the same kinds of asphalt (Figure 7). The results are shown in Figure 6. The cohesive work of the asphalts prepared with the linear SBS modifier is higher than that of the neat asphalt but lower than that of the asphalt modified by the branched SBS modifier. The results show that the SBS modifier type has a significant effect on the cohesive properties of asphalt. Specifically, the branched SBS-modified asphalt has the strongest resistance to selfcracking, the linear SBS-modified asphalt has intermediate resistance, and the neat asphalt has the least resistance to internal cracking during use. This is because the SBS modifiers comprise styrene and butadiene block copolymers, which form stable three-dimensional network structures by interlocking between styrene and butadiene blocks with the help of the highly aromatic extraction oil and stabilizer. The network structures enhance the cohesive properties of asphalt. Simultaneously, the SBS modifier absorbs the light components in the neat asphalt, which increases the asphalt polarity. Eventually, the cohesion of the asphalt increases with the addition of SBS modifier [36]. In addition, the branched SBS modifier has better modifying effects on asphalt because it has a higher molecular weight and a more compact structure, which promote the best resistance to cracking.

4.5. Effect of SBS Contents on Cohesive Work of SBS-Modified Asphalts. Figure 8 shows the relationship between the SBS content and cohesive work of SBS-modified asphalt. The cohesive work of SBS-modified asphalt gradually increases with the increase of SBS modifier. Asphalt modified with $5 \%$ SBS shows the highest resistance to cracking within the range of SBS contents, which has good resistance to water damage. Increased contents of SBS modifiers in a certain range strengthen the cross-linking and winding between the 


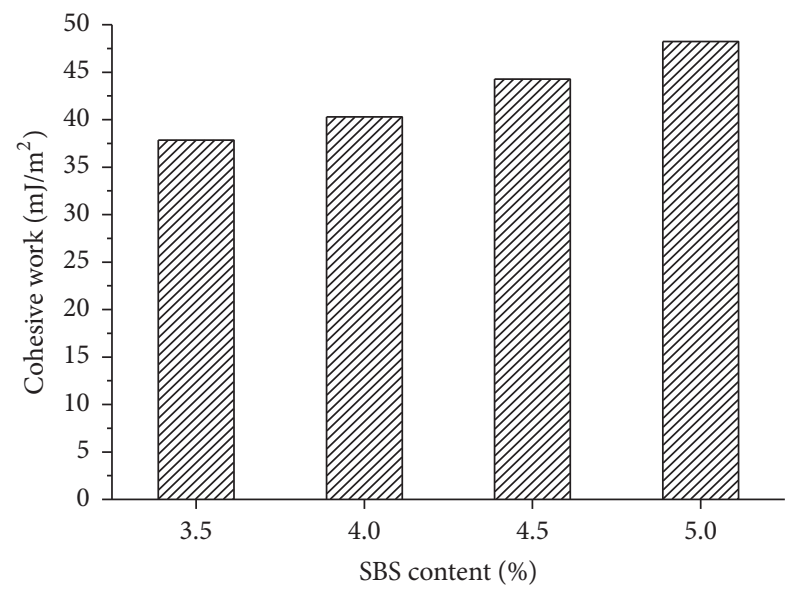

FIGURE 8: The cohesive work versus SBS content of SBS-modified asphalts.

modifier and pitch, which reinforces the three-dimensional network structure. Simultaneously, increasing the level of SBS modifier absorbs the aromatic light components of neat asphalt, which further extends the effect of SBS modification and enhances the internal intermolecular forces of the SBSmodified asphalts. Any amount of SBS improves the cohesive performance of the modified asphalt. In addition, the growth rate of the asphalt cohesive work is $6.48 \%, 9.85 \%$, and $8.93 \%$ for SBS content increases of $3.5 \%$ to $4 \%, 4 \%$ to 4.5 , and $4.5 \%$ to $5 \%$, respectively. This is because the modifier fully absorbs the aromatic components and promotes dispersibility when the amount of SBS is small, but the network structure in this range is weak, which causes cohesiveness to increase at a low rate [37].

4.6. Effect of Extraction Oil Content on Cohesive Work of SBS-Modified Asphalt. Figure 9 illustrates the changes in the cohesive work of SBS-modified asphalts with increasing contents of extraction oil. It can be seen that the cohesive work of SBS-modified asphalt increases and then decreases with increasing extraction oil contents. With $2.5 \%$ extraction oil, the cohesive work of the SBS-modified asphalt is increased by $10.87 \%$ relative to oil-free asphalt, while the cohesive work increases by $5.97 \%$ for the addition of $3.5 \%$ extraction oil compared to that with $2.5 \%$. That is because the optimal amount of furfural extraction oil promotes the swelling and dispersing of the SBS modifier, thereby assisting microstructural formation with uniform particle size, obtaining better three-dimensional network structures by interparticle interactions, and increasing the cohesive work of SBS-modified asphalt [38]. It should be noted that the cohesive work of the SBS-modified asphalt decreases for oil contents exceeding 3.5\%, dropping by $5.57 \%$ with $4.5 \%$ furfural oil. This is because of the excessive dilution of light components when the content of the highly aromatic extraction oil exceeds that required for SBS swelling and dispersing. Negative correlation relationships exist between the surface energy and aromatic content that decrease the cohesive power of SBS-modified asphalt. It can be concluded

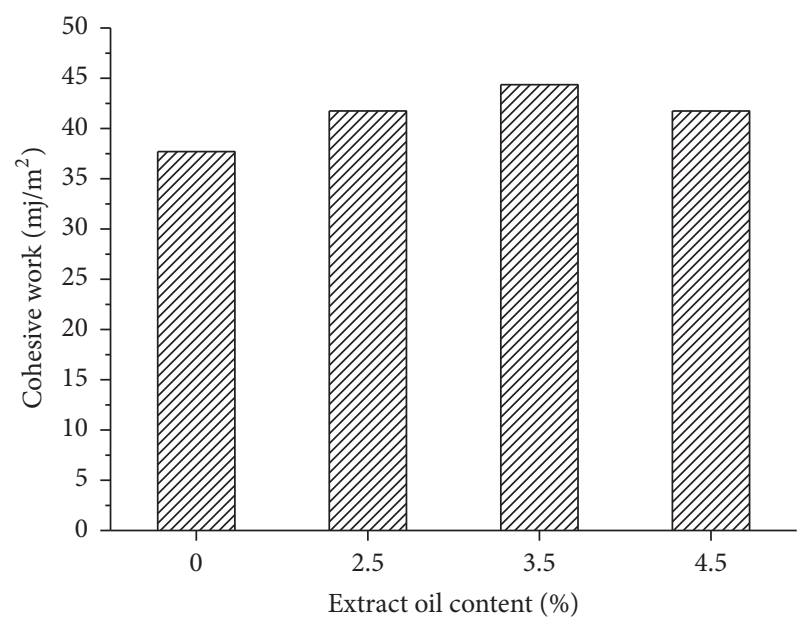

FIGURE 9: The cohesive work versus furfural extraction oil contents of SBS-modified asphalts.

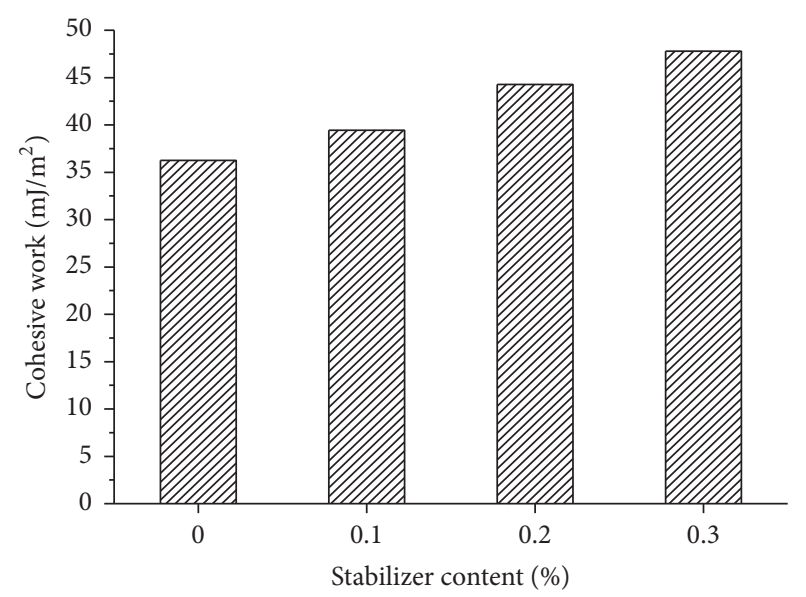

FIGURE 10: The cohesive work versus stabilizer content of SBSmodified asphalt.

from the above results that the SBS-modified asphalt with the best cohesive work can be obtained by adding the proper amount of extraction oil as a compatibility agent.

4.7. Effect of Stabilizer Content on Cohesive Work of SBSModified Asphalt. Figure 10 illustrates the changes in the cohesive work of SBS-modified asphalt with increasing stabilizer contents. The cohesive work of the SBS-modified asphalt clearly increases with increasing contents of stabilizer. The increments of cohesive work of the SBS-modified asphalts are $8.82 \%, 12.28 \%$, and $7.9 \%$ with $0.1 \%, 0.2 \%$, and $0.3 \%$ stabilizer, respectively. This is because the microstructure of the SBSmodified asphalt from the addition of stabilizer causes reactions between the SBS and neat asphalt. The distribution of SBS modifier in asphalt is changed from bead-like structures to a fine network structure, and interfacial adsorption layers form between the polymer phase and the neat asphalt phase in the modified asphalt [39]. Thus, the cohesive properties of the SBS-modified asphalt are effectively improved. 


\section{Conclusions}

(1) When evaluating surface free energy of the SBS-modified asphalt, the sessile drop method is an appropriate method because the contact angle measurements show good repeatability for the SBS-modified asphalts prepared with different raw materials and three probe liquids.

(2) The cohesive work of SBS-modified asphalt can be increased by selection the most suitable bitumen and SBS modifier to improve the compatibility. And the cohesive properties of asphalt are maximal with branched SBS, intermediate with linear SBS, and minimal in neat asphalt.

(3) The addition content of admixtures, including SBS modifier, stabilizer, and extraction oil can affect cohesive work of SBS-modified asphalt differently. The cohesive work of SBS-modified asphalt increases with the increase of SBS modifier and stabilizer contents, while it increases and then decreases with increases of extraction oil content.

(4) The writers envision that continued development of other intuitive detection method to cohesion characteristics of SBS-modified asphalt in the future will contribute toward implementation of the moisture susceptibility.

\section{Conflicts of Interest}

The authors declare that there are no conflicts of interest regarding the publication of this paper.

\section{Acknowledgments}

The research work reported in this paper was supported by the National Natural Science Foundation of China (51408287 and 51668038), Rolls Supported by Program for Changjiang Scholars and Innovative Research Team in University (IRT_15R29), the Distinguished Young Scholars Fund of Gansu Province (1606RJDA318), the Natural Science Foundation of Gansu Province (1506RJZA064), Excellent Program of Lanzhou Jiaotong University (201606), and Foundation of A Hundred Youth Talents Training Program of Lanzhou Jiaotong University.

\section{References}

[1] B. Li, J. Yang, Z. Chen, and H. Li, "Microstructure morphologies of asphalt binders using atomic force microscopy," Journal Wuhan University of Technology, Materials Science Edition, vol. 31, no. 6, pp. 1261-1266, 2016.

[2] G. D. Airey, "Styrene butadiene styrene polymer modification of road bitumens," Journal of Materials Science, vol. 39, no. 3, pp. 951-959, 2004.

[3] X. Zhao, S. Wang, Q. Wang, and H. Yao, "Rheological and structural evolution of SBS modified asphalts under natural weathering," Fuel, vol. 184, pp. 242-247, 2016.

[4] J. T. Kim, J. Baek, H. Lee, and Y. Ji, "Fatigue performance evaluation of SBS modified mastic asphalt mixtures," Construction \& Building Materials, vol. 48, no. 11, pp. 908-916, 2013.

[5] F. Gahvari, "Effects of thermoplastic block copolymers on rheology of asphalt," Journal of Materials in Civil Engineering, vol. 9, no. 3, pp. 111-116, 1997.
[6] G. Polacco, S. Filippi, F. Merusi, and G. Stastna, "A review of the fundamentals of polymer-modified asphalts: asphalt/polymer interactions and principles of compatibility," Advances in Colloid and Interface Science, vol. 224, pp. 72-112, 2015.

[7] A. Modarres, "Investigating the toughness and fatigue behavior of conventional and SBS modified asphalt mixes," Construction and Building Materials, vol. 47, pp. 218-222, 2013.

[8] D. Niu, S. Han, K. Chen, and O. Xu, "Study on influences of key process parameters on SBS modified asphalt," Changan Daxue Xuebao, vol. 34, no. 3, p. 16, 2014.

[9] W. Yin, F. Ye, and H. Lu, "Establishment and experimental verification of stability evaluation model for SBS modified asphalt: Based on quantitative analysis of microstructure," Construction and Building Materials, vol. 131, pp. 291-302, 2017.

[10] F. Dong, W. Zhao, Y. Zhang et al., "Influence of SBS and asphalt on SBS dispersion and the performance of modified asphalt," Construction and Building Materials, vol. 62, pp. 1-7, 2014.

[11] D. O. Larsen, J. L. Alessandrini, A. Bosch, and M. S. Cortizo, "Micro-structural and rheological characteristics of SBSasphalt blends during their manufacturing," Construction and Building Materials, vol. 23, no. 8, pp. 2769-2774, 2009.

[12] H. Fu, L. Xie, D. Dou, L. Li, M. Yu, and S. Yao, "Storage stability and compatibility of asphalt binder modified by SBS graft copolymer," Construction and Building Materials, vol. 21, no. 7, pp. 1528-1533, 2007.

[13] T. Wang, T. Yi, and Z. Yuzhen, "The compatibility of SBSmodified asphalt," Petroleum Science and Technology, vol. 28, no. 7, pp. 764-772, 2010.

[14] P. Yang, D. Liu, F. Yan et al., "Application of the compatibility theory and the solubility parameter theory in SBS modification asphalt," Petroleum Science and Technology, vol. 20, no. 3-4, pp. 367-376, 2002.

[15] M. Liang, P. Liang, W. Fan et al., "Thermo-rheological behavior and compatibility of modified asphalt with various styrenebutadiene structures in SBS copolymers," Materials and Design, vol. 88, pp. 177-185, 2015.

[16] L. Wang and C. Chang, "Rheological evaluation of polymer modified asphalt binders," Journal Wuhan University of Technology, Materials Science Edition, vol. 30, no. 4, pp. 695-702, 2015.

[17] R. A. Tarefder and A. M. Zaman, "Nanoscale evaluation of moisture damage in polymer modified asphalts," Journal of Materials in Civil Engineering, vol. 22, no. 7, pp. 714-725, 2010.

[18] M. Arabani and G. H. Hamedi, "Using the surface free energy method to evaluate the effects of liquid antistrip additives on moisture sensitivity in hot mix asphalt," International Journal of Pavement Engineering, vol. 15, no. 1, pp. 66-78, 2014.

[19] G. Xu and H. Wang, "Study of cohesion and adhesion properties of asphalt concrete with molecular dynamics simulation," Computational Materials Science, vol. 112, pp. 161-169, 2016.

[20] B. Li, Z. Zhang, and X. Liu, "Adhesion in SBS modified asphalt containing warm mix additive and aggregate system based on surface free theory," Cailiao Daobao, vol. 31, no. 2, pp. 115-120, 2017.

[21] E. Masad, C. Zollinger, R. Bulut et al., "Characterization of HMA moisture damage using surface energy and fracture properties," in Proceedings of the Association of Asphalt Paving Technologists -Proceedings of the Technical Sessions 2006 Annual Meeting, pp. 713-754, March 2006.

[22] Y. Veytskin, C. Bobko, C. Castorena, and Y. R. Kim, "Nanoindentation investigation of asphalt binder and mastic cohesion," Construction and Building Materials, vol. 100, no. 4, pp. 163-171, 2015. 
[23] A. Bhasin, D. N. Little, K. L. Vasconcelos, and E. Masad, "Surface free energy to identify moisture sensitivity of materials for asphalt mixes," Transportation Research Record, vol. 2001, no. 1, pp. 37-45, 2007.

[24] J. Wei, Y. Zhang, and J. Youtcheff, "Determination of the surface free energy of asphalt binders by sessile drop method," in Acta Petrolei Sinica (Petroleum Processing Section), vol. 25, pp. 207215, 2 edition, 2009.

[25] D. Cheng, D. N. Little, R. L. Lytton et al., "Use of surface free energy properties of the asphalt-aggregate system to predict moisture damage potential," in Proceedings of the Asphalt Paving Technology 2002, pp. 59-88, March 2002.

[26] Y. Tan and M. Guo, "Using surface free energy method to study the cohesion and adhesion of asphalt mastic," Construction and Building Materials, vol. 47, no. 5, pp. 254-260, 2013.

[27] M. R. Kakar, M. O. Hamzah, M. N. Akhtar, and D. Woodward, "Surface free energy and moisture susceptibility evaluation of asphalt binders modified with surfactant-based chemical additive," Journal of Cleaner Production, vol. 112, pp. 2342-2353, 2016.

[28] J. Wei, Y. Zhang, and J. S. Youtcheff, "Effect of polyphosphoric acid on the surface free energy of asphalt binders," Acta Petrolei Sinica (Petroleum Processing Section), vol. 27, no. 2, pp. 280-285, 2011.

[29] F. Ma, J.-X. Hao, Z. Fu, L.-L. Wang, and L.-B. Wang, "Surface free energy analysis of asphalt modified with natural asphalt," Journal of Traffic and Transportation Engineering, vol. 15, no. 1, pp. 18-24, 2015.

[30] F. Fowkes, "Attractive forces at interfaces," Industrial \& Engineering Chemistry, vol. 56, no. 12, pp. 40-52, 1964.

[31] R. J. Good, "Contact Angle, Wetting, and Adhesion: A Critical Review," Journal of Adhesion Science and Technology, vol. 6, no. 12, pp. 1269-1302, 1992.

[32] C. J. van Oss, R. J. Good, and M. K. Chaudhury, "Additive and nonadditive surface tension components and the interpretation of contact angles," Langmuir, vol. 4, no. 4, pp. 884-891, 1988.

[33] D. K. Owens and R. C. Wendt, "Estimation of the surface free energy of polymers," Journal of Applied Polymer Science, vol. 13, no. 8, pp. 1741-1747, 1969.

[34] D. Y. Kwok and A. W. Neumann, "Contact angle measurement and contact angle interpretation," Advances in Colloid and Interface Science, vol. 81, no. 3, pp. 167-249, 1999.

[35] A. W. Hefer, A. Bhasin, and D. N. Little, "Bitumen surface energy characterization using a contact angle approach," Journal of Materials in Civil Engineering, vol. 18, no. 6, pp. 759-767, 2006.

[36] S. Li, Q. Lin, and S. Dong, "Progress in mechanism of SBSmodified asphalts," Chinese Polymer Bulletin, vol. 34, no. 5, pp. 14-19, 2008.

[37] J.-A. Yuan, D. Ji, and Z.-G. Zhu, "Effect of different dosage SBS on properties of modified asphalt," Journal of Chang'an University (Natural Science Edition), vol. 25, no. 3, pp. 19-48, 2005.

[38] X. Li and J. Cheng, "Influence of furfural extract oil on property of SBS modified asphalt," Petroleum Asphalt, vol. 25, no. 3, pp. 65-68, 2011.

[39] P. Xiong and P. Hao, "Measures and mechanism analysis of improving the storage stability of styrene-butadiene-styrene polymer modified asphalt," Journal of Tongji University (Natural Science), vol. 34, no. 5, pp. 613-618, 2006. 

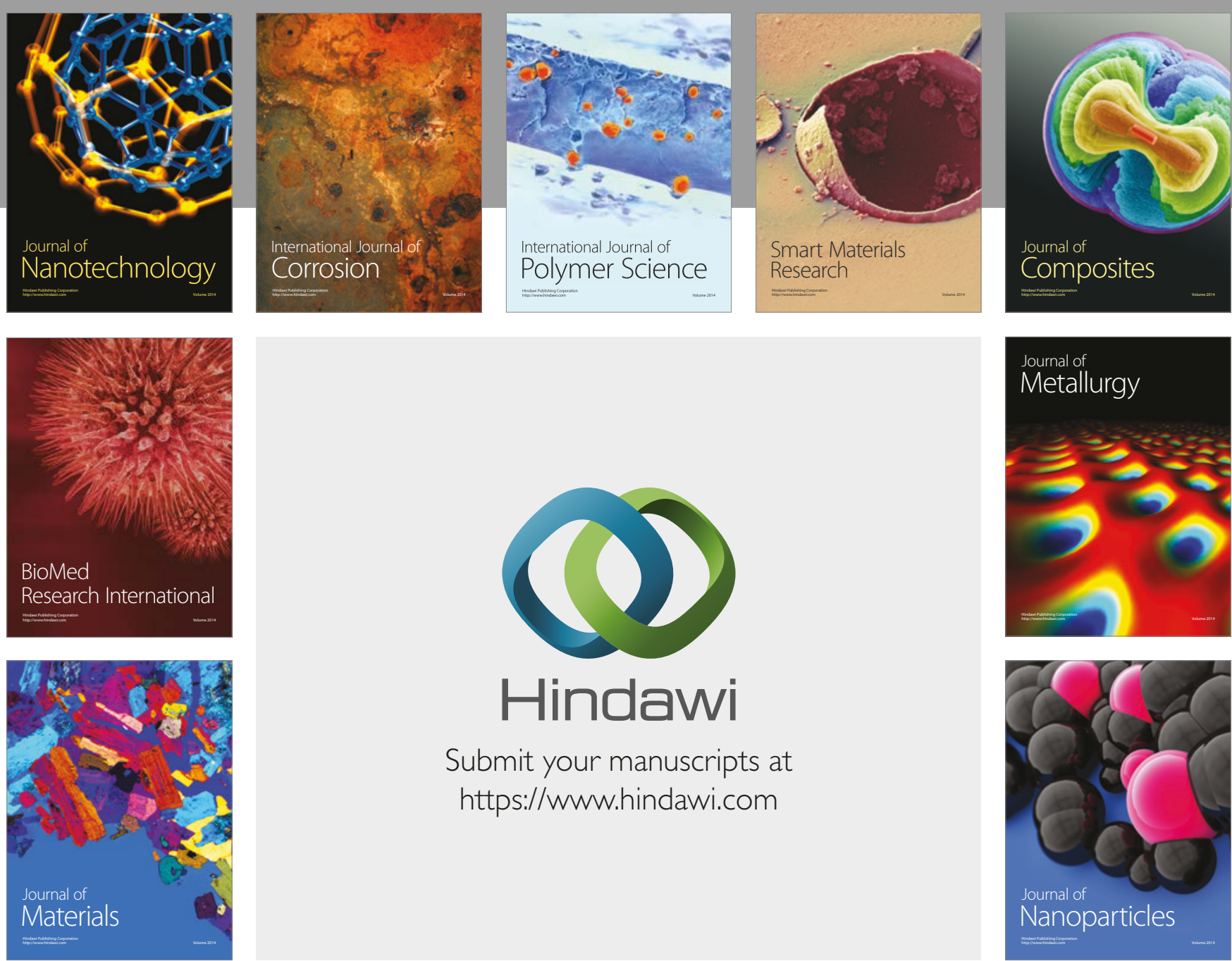

\section{Hindawi}

Submit your manuscripts at

https://www.hindawi.com
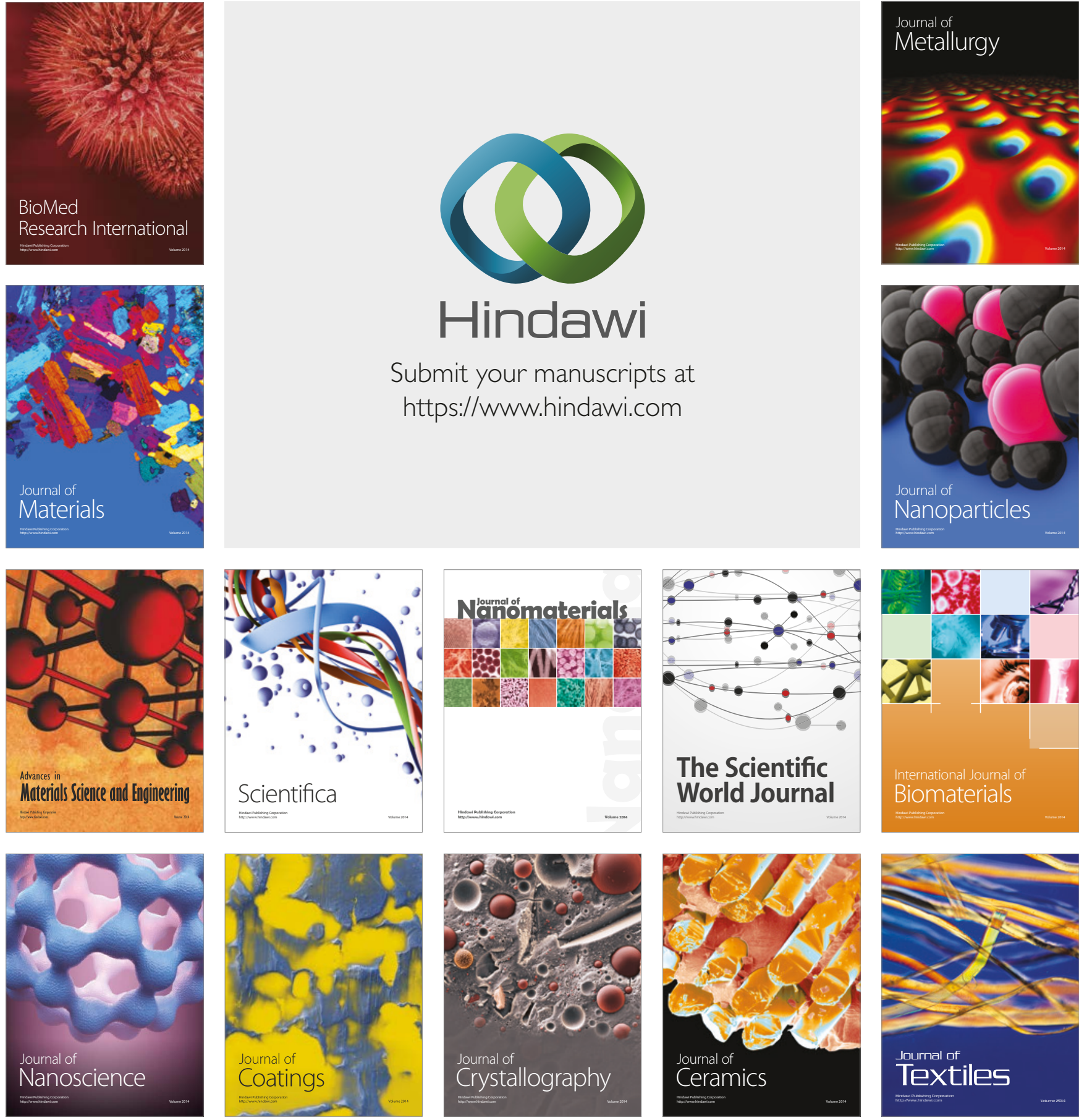

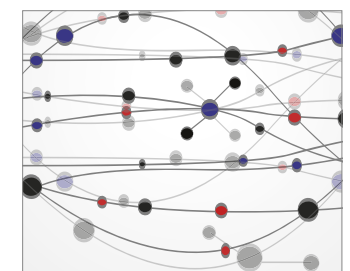

The Scientific World Journal
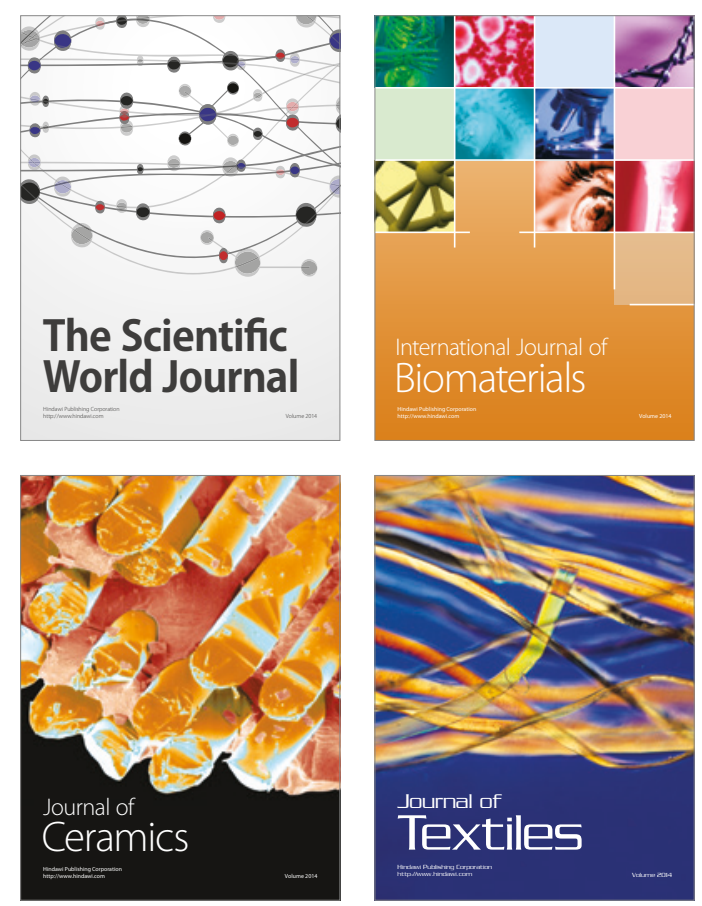